IFAS Extension

\title{
Pest Management Perceptions and Practices for Equine Farms in North and Central Florida ${ }^{1}$
}

\author{
Erika T. Machtinger, Norman C. Leppla, and Cindy Saunders ${ }^{2}$
}

\section{Introduction}

Integrated pest management (IPM) for equine farms requires accurate diagnosis of pest problems and the coordinated use of science-based management practices. Currently, knowledge is limited about pest problems faced by horse owners in Florida and management of pests on equine facilities. To develop an effective IPM system for horse farms, horse owners' pest problems must be identified, and current management practices of equine facilities must be understood.

Equine facilities have unique pest management problems due to facility structure and horse husbandry practices. In Florida, homes on small equine farms are generally located in close proximity to pastures, stalls or run-in sheds, manure piles, and other fly breeding habitats (Figure 1). Because of this association, homeowners have a high risk of exposure to pathogens that can be transmitted by filth flies to humans (Förster et al. 2007). Substrates, such as straw or sand, that are used in equine husbandry vary significantly between horse farms and other livestock facilities. Substrate type and management can influence the development of some insect pests on a property. Additionally, typical areas surveyed for biological control agents and filth fly development on cattle or poultry operations, such as silage areas, calf hutches, and laying houses, are not found on equine facilities. These differences make it challenging to adapt insect pest management protocols for equine farms that were developed on other livestock facilities.

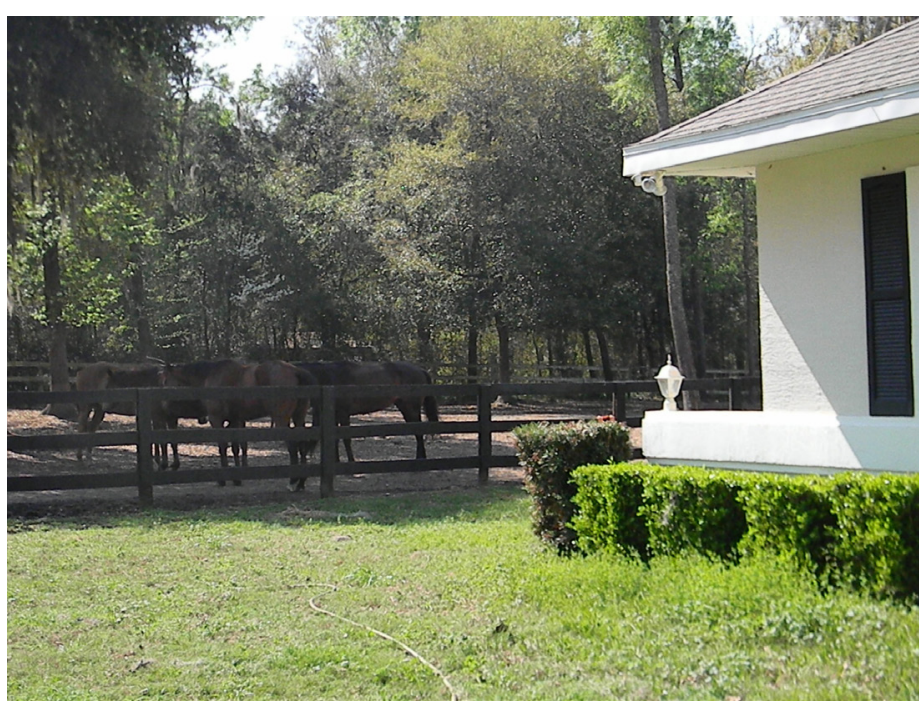

Figure 1. Single-family homes are often located adjacent to horse paddocks or stables in equine farms in Florida.

Credits: Erika T. Machtinger

While many control methods are available for managing insect pests affecting horses, there is insufficient information on the effectiveness of most of them. Commercial products used by horse owners for pest control include biological control agents, chemical sprays, personal protection devices (fly masks, wraps, and blankets), baits, and traps. Many of these products and other components of an IPM system currently may be over- or underused by Florida equestrians because of the lack of information and training on developing IPM plans for equine farms.

1. This document is ENY-2028, one of a series of the Entomology and Nematology Department, Florida Cooperative Extension Service, Institute of Food and Agricultural Sciences, University of Florida. Original publication date March 2013. Visit the EDIS website at http://edis.ifas.ufl.edu.

2. Erika T. Machtinger, PhD student, Entomology and Nematology Department; Norman C. Leppla, professor, program director-IPM Florida, Entomology and Nematology Department IFAS, University of Florida, Gainesville FIL 32611 and Cindy Saunders, Alachua County Extension director. 
Although horses are numerous in Florida and important to the state economy, research on managing their pests is limited, and practices are excluded from national surveys. The 2006 USDA survey, which details management practices on equine farms nationwide, did not include properties with fewer than five horses. This restriction potentially eliminated approximately half of the properties in the United States that house horses, certainly the small equine farms, and presents an inaccurate analysis of the needs and practices of the equine industry.

The purpose of this survey was to gain knowledge about IPM use on equine farms in Florida and use it to guide research and Extension activities. The objectives were to determine the perceived pest problems and current pest management practices used on equine farms and to identify the research and Extension needs of horse and facility owners in North and Central Florida.

\section{Survey Design}

The survey was conducted from 15 November, 2010 to 20 June, 2011 by using Survey Monkey (www.surveymonkey. com) to collect and analyze responses from anonymous respondents. The survey link was sent to 16 major equine organizations in north and central Florida, including regional shows, clubs, and associations, requesting that it be distributed to their members. It also was provided to county Extension agents and printed in the Central Florida Equine Magazine. The survey had three sections: 1) basic demographic information of the participants, 2) pest problems and management practices on their facilities, and 3) opinions on the quality and availability of research and Extension materials.

\section{Survey Results}

Horse owners in north and central Florida attempt to manage their pest insects with a variety of methods, many of which could be components of an IPM program. However, based on survey responses, many opportunities are available for research and Extension programming on IPM practices for more effectively managing pests on equine farms. Responses to the survey questions ranged from 274 to 299; however, not every respondent answered every question. Therefore, response percentages were used to analyze the data.

\section{A Diverse Clientele}

The equine industry in north and central Florida represents a diverse sector of agriculture (Table 1). There were many differences in property acreage and number of horses, and over 21 riding disciplines were cited. More than $90 \%$ of the survey respondents were pleasure riders or engaged in performance activities, which was significantly higher than the 2005 American Horse Council survey results that found $60 \%$ of Florida horses were used in recreation and showing. Equestrians participating in these activities are likely to be affiliated with at least one organization or group that had access to the survey; therefore, it was expected that higher numbers might respond. Most facilities were 10 acres or less (56.4\%), housing between one and five horses (63.7\%).

\section{Perceived Pest Problems}

Pest problems clearly were observed seasonally in Florida equine facilities. Overwhelmingly, respondents said they experienced pest pressure in the summer months (June, July and August) (86.1\%) (Figure 1). This response was expected because insect pests in Florida are aided in development by high humidity and temperatures, particularly in the summer months.

Many arthropods were indicated as major pests on equine farms. The most common pest species were mosquitoes, stable flies, and gnats, with many write-in responses for "yellow fly" and the so-called "cow fly" that respondents may have applied to the horn fly, stable fly, or even house fly (Figure 2). The colloquial term "cow fly" typically refers to the horn flies often found on the backs of cows. Midges, $\mathrm{Cu}$ licoides spp., "yellow fly," and "cow fly" were options in the base question represented as their correct common names (deer fly and horn fly, respectively). This variability in name recognition demonstrated that many respondents may not be familiar with common names and, therefore, use colloquial terminology. This potential confusion was observed again in the follow-up question regarding pest identification. Respondents considered stable flies a problem (63.1\%) and thought they could identify them accurately (61.5\%). However, this response is surprising because stable flies are not often observed feeding on horses. Although stable flies can be found on horses, particularly feeding on the forelegs (Mullens et al. 1988), they do not linger, preferring to rest on nearby walls or fence lines (Gerry et al. 2007; Mullens et al. 1988), making it unlikely that horse owners would observe and correctly identify them. Additionally, although respondents reported most pest pressure in the summer, stable flies are most abundant in late winter and spring on horse farms in Florida (Machtinger 2011; Pitzer et al. 2011). 
Respondents may be observing horn flies or house flies and mistaking them for stable flies or they may assume that flies

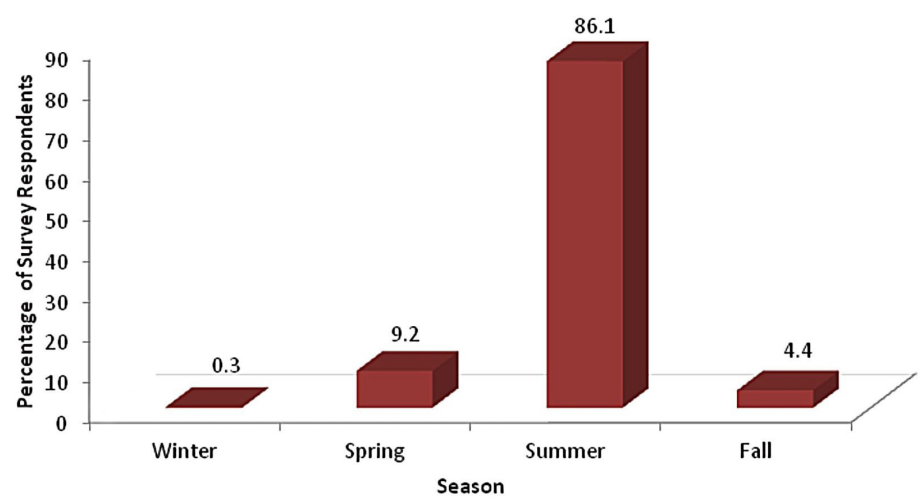

Figure 2. Seasons when survey respondents perceived the most pest problems.

found in the stable are classified as "stable" flies. Based on responses, the ability of the survey population to accurately identify pest species is questionable and presents an opportunity for education on insect identification.

\section{Pest Management Practices and Opinions}

Pests were not monitored by the majority of the survey takers. Over $76 \%$ of respondents did not monitor pest populations on their properties during the year, mainly because they lack knowledge about the required methods and materials (59.1\%) (Figure 3). Owners of small equine facilities are frequently employed full-time away from the operation. Smaller boarding and training facilities that provide riding lessons and other services are often family-run, and these families may lack time to learn and implement monitoring methods and gather the required information. When asked to describe monitoring techniques in the comment box, many of the respondents listed some form of control, such as biological control, traps, or insecticides. In the context of IPM, monitoring requires regular observations to determine the abundance of pests on a property. These observations provide the basis for pest management decision making and action relative to economic or damage thresholds (Higley and Pedigo 1996). Based on these responses, it is clear that monitoring in the context of IPM is not widely understood by equine farm owners.

Horse owners demonstrated a very low tolerance for pests. Survey respondents were asked how many pests they would tolerate around their animals, or their action threshold, and the majority responded with less than 10 pests. Unfortunately, action thresholds have not been determined for horses because the economic or damage levels are difficult
Which pests do you believe give you the most problems? $\square$ Which pests do you believe you can accurately identify?

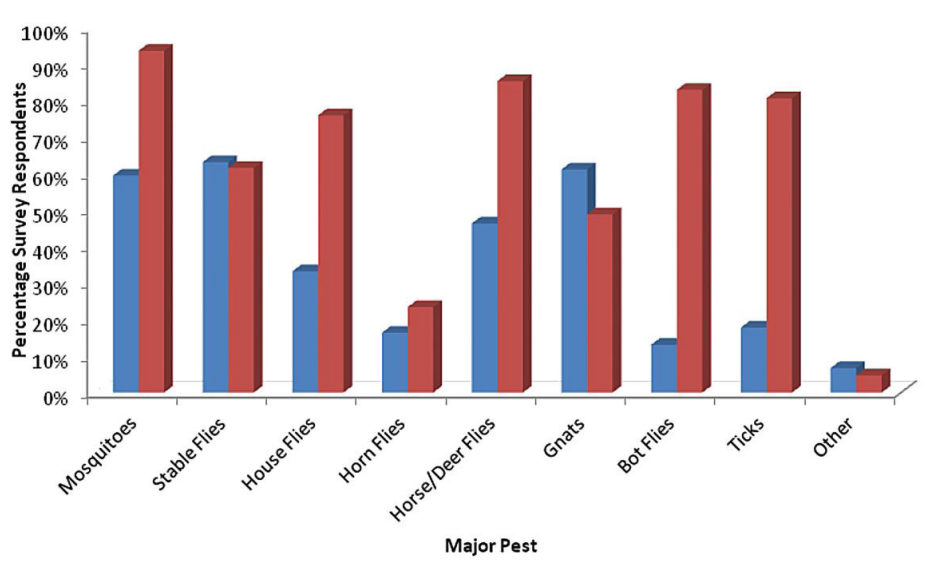

Figure 3. Comparison of perceived pest problems and ability to identify pests. Respondents were allowed to select multiple pests.

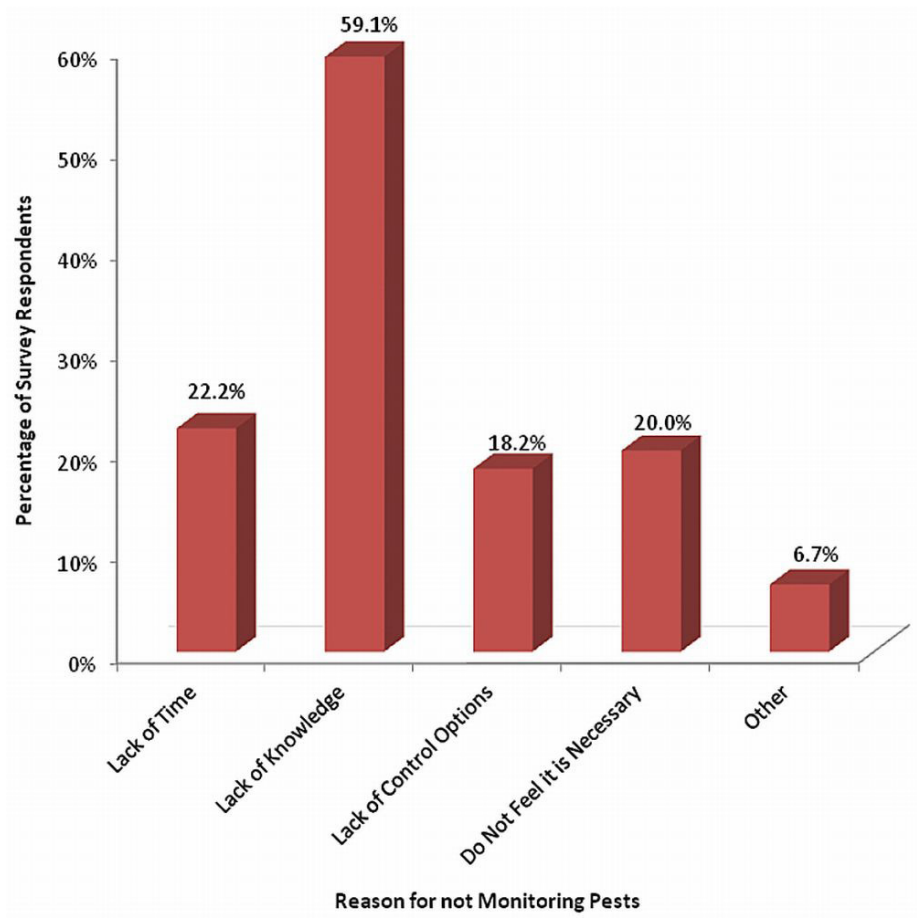

Figure 4. Survey respondent reasons for not monitoring pests on equine farms.

to assess quantitatively in terms of losses. In this survey, it might have been difficult for owners to assign numbers of pests around their animals into the groupings we provided, so they answered 10 or lower, wishing to convey a low but not necessarily accurate number. Future research on economic losses to horse owners attributed to equine pests may further guide the research community on the needs of this sector of agriculture and provide action threshold guidelines to horse owners.

Manure management is one of the most important sanitation practices in IPM of filth fly pests, such as house and 
stable flies, and some form was practiced by virtually all the respondents (Figure 4). All but three of the 272 respondents to the pest problems and management practices section of the survey managed their manure and bedding waste, suggesting that they may be aware that it could attract and support filth fly pests. The most common methods of waste disposal were distribution with a spreader (49\%), dragging pastures $(22.1 \%)$, placing it in a pile $(24.8 \%)$, and active composting (25.9\%). Apparently, owners and operators of equine facilities are attuned to managing manure and bedding waste to maintain the health and welfare of their animals. Farms practicing rigorous sanitation may limit breeding of some filth flies (Kaufman et al. 2005), and manure management should continue to be encouraged on equine facilities.

Owners of an equine facility typically require more than one method to control pest insects on their farm. Survey respondents were asked to indicate how many control methods were used (Figure 5). Most of the respondents used two (32.9\%) or three methods $(27.8 \%)$ and about half as many used one (11.9\%) or four (15.3\%). The use of five or six methods was rare and just one of the respondents reported using seven. Horse owners were not asked why they used more than one method for controlling insect pests, but it can be assumed that no single method is adequately effective for all pest species. Additionally, they may be attempting to control pests in different locations where different methods are required, e.g., in barns, on horses, around feeding areas. The abundance of pest species varies with season, so specific methods may be more effective at certain times of the year.

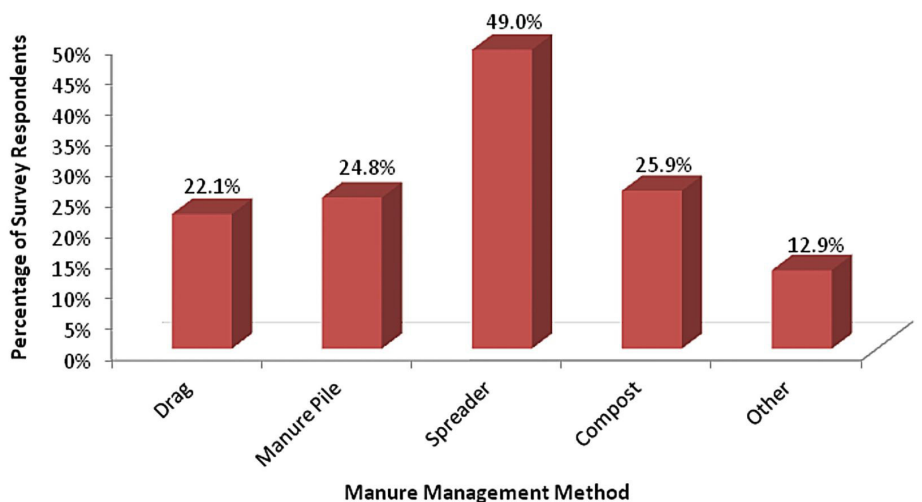

Figure 5. Types of manure management methods used in equine farms. Respondents were allowed to select multiple pests.

The survey respondents were asked to indicate the pest control methods they used most often to manage insect pests (Figure 6). Insecticide application was the predominant method of pest control (95.9\%). Physical exclusion with fly masks (66.2\%) was also commonly practiced, although respondents also used traps (38.0\%), biological control (22.0\%), and feed-through insecticide control (14.6\%). Insecticides and repellents are commonly marketed to the equine industry, and the high numbers of respondents using insecticides suggest an over-reliance on chemical control. Horse owners clearly prefer conventional pest control methods targeted at adult insects but try options to control immature insects. Incorporating methods for controlling larvae is useless if insect pests are not breeding

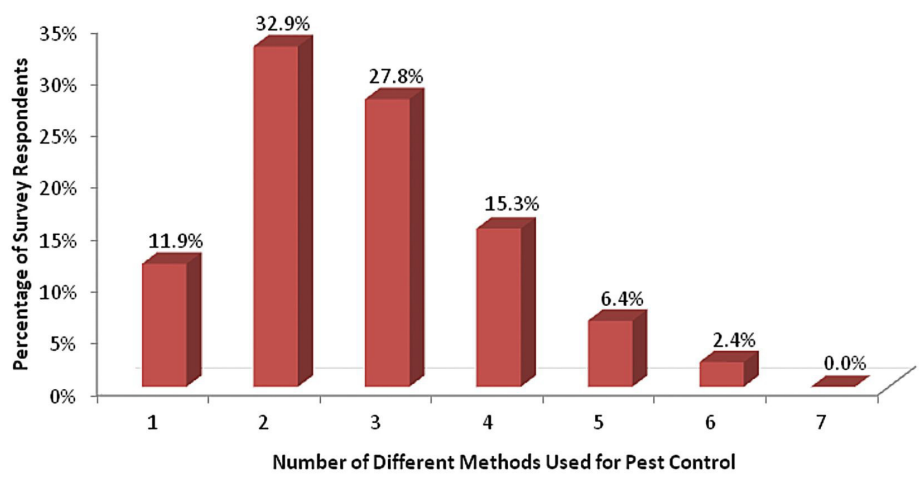

Figure 6. The percentage of survey respondents that used one or more methods of pest control.

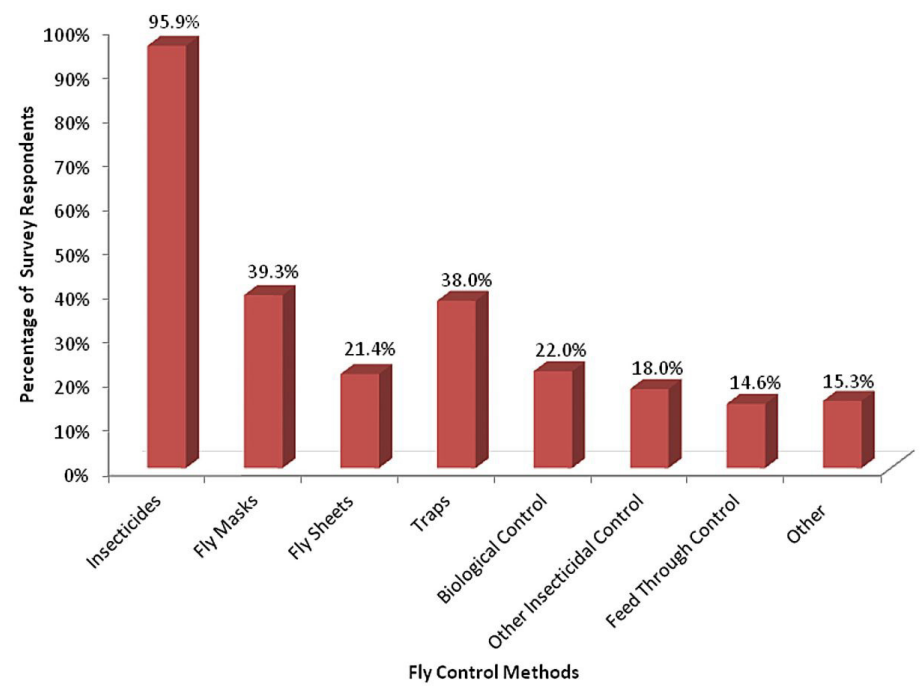

Figure 7. Types of pest control methods used on equine farms in north and central Florida. Respondents were allowed to select multiple types of pest control methods

on equine farms. Because of a lack of monitoring, respondents were uninformed about pest type or abundance on their property. Nevertheless, some respondents expressed a willingness to use expensive and potentially harmful insecticides with no substantiated basis for their need or efficacy. 
Annual expenditures by horse owners for pest control seemed unnecessarily high. About $74 \%$ of respondents spent in excess of $\$ 100$ and 33.0\% more than $\$ 200$ annually on fly control products (Figure 7). Even with multiple methods and high annual costs, an overwhelming majority found products to be only somewhat effective $(72.3 \%)$. Horse owners attempting to manage pest problems might find a product marginally effective but continue to purchase and use more of it until some level of satisfaction in control is reached. This level of use and the associated expense may be due to the varying sizes of horse farms surveyed in terms

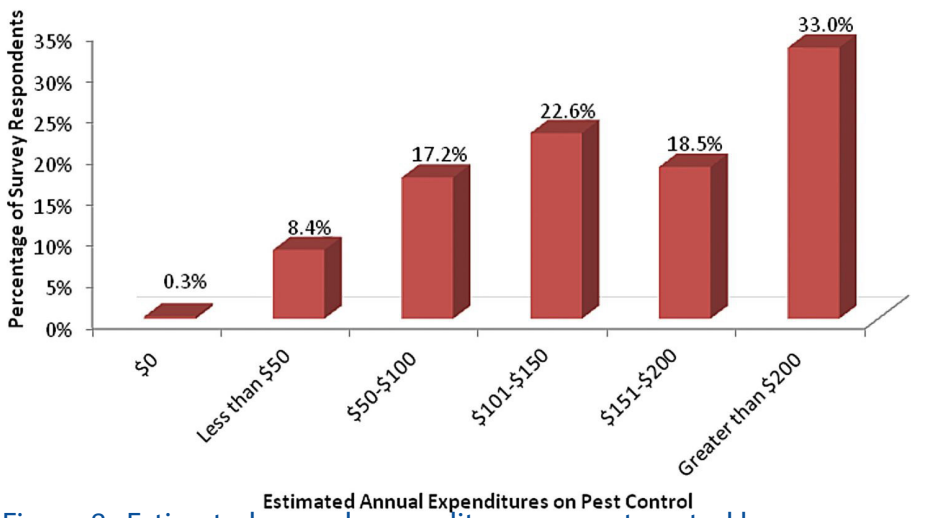

Figure 8. Estimated annual expenditures on pest control by survey respondents.

of horse numbers, or potentially to horse owners using large amounts of a product or multiple products. Clearly, horse owners in Florida are willing to pay for pest control on their farms. However, these expenses may be excessive or unnecessary, depending on the farm. Educating owners about pests and pest control methods could help minimize expenses while maximizing control as part of an effective IPM plan.

\section{Research and Extension Requests}

Horse owners displayed significant preferences in Research and Extension (Table 2), with more than half of the survey respondents indicating that current research was not meeting their needs (54.3\%). Horse owners were asked to provide feedback on their research preferences. The high percentage of pesticide use suggested that the survey population had a positive attitude about chemical control. However, over $80 \%$ of respondents requested that more research be conducted on biological control, and non-toxic solutions were the most popular write-in answer. When asked which sources they most frequently use to obtain information on pest control, the most common answer was the internet. Respondents also consulted in similar frequencies with veterinarians, employees at feed stores, friends, and Extension agents. This survey was conducted online and, since the internet was the primary source of information used by facility owners, it is likely that they were predisposed to internet browsing and proactive in researching pest control products. The distinct preference and requests for information on biological control and non-toxic solutions found in this survey should help to establish Research and Extension priorities.

\section{Future Educational Opportunities and Conclusions}

The results of this survey indicated that more research and Extension efforts are warranted in support of the small equine farm sector. Many equine property owners have insufficient knowledge of the identification, biology, and presence of filth fly pests on their properties, which is required to develop successful IPM programs. They continue to rely on insecticides because they lack adequate understanding of available alternatives. Although a comprehensive understanding of IPM practices was not demonstrated by respondents, a willingness to protect themselves and their animals was apparent. A concerted effort should be made to educate equine facility owners about the benefits of carefully planned IPM programs for managing external pests of horses and to provide online resources for proactive farm owners and managers. This need for pest management information presents an opportunity for increasing production and distribution of IPM educational materials to Extension agents, equine farm owners, and large animal veterinarians.

\section{Selected Educational Links}

IPM Florida http://ipm.ifas.ufl.edu/

External Parasites on Horses http://edis.ifas.ufl.edu/ig139

External Parasites around Animal Facilities http://edis.ifas. ufl.edu/ig054

Deer Flies, Yellow Flies and Horse Flies, Chrysops, Diachlorus, and Tabanus spp. (Insecta: Diptera: Tabanidae) http:// edis.ifas.ufl.edu/in 155

Pesticide Safety around Animals http://edis.ifas.ufl.edu/ ig 128 


\section{Selected References}

American Horse Council (AHC). 2005. The Economic Impact of the Horse Industry in the United States. AHC, Washington, D.C.

Coble, H. D., and E. E. Ortman. 2009. The USA IPM Roadmap. In E.B. Radcliff, W. D. Hutchison, and R. E. Canceldo (eds.), Integrated Pest Management: Concepts, Tactics, Strategies and Case Studies. Cambridge University Press. Cambridge, England.

Florida Department of Agriculture and Consumer Services (FDACS). 2004. Florida Horse Industry. FDACS. Tallahassee, FL.

Förster, M., S. Klimpel, H. Mehlhorn, K. Sievert, S. Messler, and K. Pfeffer. 2007. Pilot study on synanthropic flies (e.g. Musca, Sarcophaga, Calliphora, Fannia, Lucilia,Stomoxys) as vectors of pathogenic microorganisms, Parasitol. Res. 101: 243-246.

Gerry, A. C., N. G. Peterson, and B. A. Mullens. 2007. Predicting and controlling stable flies on California dairies. University of California, Agriculture and Natural Resources. Communication Services. ANR Publication 8258.

Higley L. G., and L. P. Pedigo. 1996. Economic Thresholds for Integrated Pest Management. University of Nebraska Press. Lincoln, NE.

Machtinger, E. T. 2011. Studies on the field ecology, breeding biology and parasitism of house flies, Musca domestica and stable flies, Stomoxys calcitrans, (Diptera: Muscidae) to improve integrated pest management for North Florida small equine farms. M.S. Thesis, University of Florida, Gainesville, FL.

Mullens, B. A., J. A. Meyer, and S. E. Bishop.1988. Stable fly activity on California dairies. California Agriculture 42: $20-21$.

Pitzer, J. B., P. E. Kaufman, J. A. Hogsette, C. J. Geden, and S. H. Tenbroeck. 2011. Seasonal abundance of stable flies and filth fly pupal parasitoids (Hymenoptera: Pteromalidae) at Florida equine facilities. J. Econ. Entomol. 104: 1108-1115.

Reinmeyer, C. R., and B. W. Rohrbach. 1990. A survey of equine parasite control practices in Tennessee. J. Am. Vet. Med. Assoc. 196: 712-716.
(USDA) United States Department of Agriculture. 2006. Equine 2005, Part II: Changes in the U.S. Equine Industry, 1998-2005. USDA-APHIS-VS, CEAH \#N452-0307. Fort Collins, CO. 
Table 1. Equine activities, property descriptions, and number of horses maintained by survey respondents.

\begin{tabular}{|c|c|c|}
\hline Parameter & Number of Respondents & $\begin{array}{l}\text { Percentage of } \\
\text { Respondents }\end{array}$ \\
\hline \multicolumn{3}{|l|}{ Equine activity ( $n=283$ ) } \\
\hline Pleasure riding & 139 & 49.1 \\
\hline Performance horses & 118 & 41.7 \\
\hline Other & 26 & 9.2 \\
\hline \multicolumn{3}{|l|}{ Property status ( $n=284)$} \\
\hline Barn/facility owner & 240 & 84.5 \\
\hline Boarder at a facility & 36 & 12.7 \\
\hline Rider at a facility & 3 & 1.1 \\
\hline Other & 5 & 1.8 \\
\hline \multicolumn{3}{|l|}{ Property acreage $(n=282)$} \\
\hline $1-10$ acres & 159 & 56.4 \\
\hline $11+$ & 123 & 43.6 \\
\hline \multicolumn{3}{|l|}{ Number of horses $(n=294)$} \\
\hline $1-5$ horses & 181 & 63.7 \\
\hline $6+$ & 103 & 36.3 \\
\hline
\end{tabular}

Table 2. Types of research and Extension information requested by the respondents ${ }^{1}$.

\begin{tabular}{|c|c|c|}
\hline Type of Research or Information & $\begin{array}{l}\text { Number of } \\
\text { Respondents }\end{array}$ & $\begin{array}{c}\text { Percentage of } \\
\text { Respondents }\end{array}$ \\
\hline \multicolumn{3}{|l|}{ Research Meets Needs $(n=280)$} \\
\hline No & 152 & 54.3 \\
\hline Yes & 128 & 45.7 \\
\hline \multicolumn{3}{|l|}{ Research Requests ( $n=276$ ) } \\
\hline Biological control & 231 & 80.2 \\
\hline Cultural control methods & 140 & 48.6 \\
\hline Insecticides & 121 & 40.0 \\
\hline Trapping options & 61 & 22.1 \\
\hline Physical barriers & 23 & 8.0 \\
\hline Other & 11 & 3.8 \\
\hline \multicolumn{3}{|l|}{ Extension Requests ( $n=277$ ) } \\
\hline Biological control & 172 & 62.1 \\
\hline Pesticide use & 112 & 40.4 \\
\hline Cultural control methods & 106 & 38.3 \\
\hline Trapping options & 83 & 30.0 \\
\hline Identification & 62 & 22.4 \\
\hline Sampling methods & 61 & 22.0 \\
\hline
\end{tabular}

